Our findings fail to show with any certainty whether viruses play a part in the pathogenesis of acute otitis media. An appreciable rise in titre to antibodies against a respiratory virus was found in $15(25 \%)$ of the 60 patients tested: four had received antibiotics alone and 11 myringotomy alone or in combination. Pathogenic bacteria were isolated from the middle ear in six of these 11 patients.

Complications developed in few cases. The two patients with mastoiditis, who also were identified easily, responded well to amoxycillin. Regardless of the type of treatment, the incidence of mastoiditis has decreased greatly over the past few decades; before 1946 the incidence in patients with otitis was $10-44 \%$; in 1954 Rudberg could still report an incidence of $17 \% .^{9}$ The use of antibiotics in all cases of otitis cannot be the cause of this considerable decrease; if it were the decrease would have been less pronounced in the Netherlands, where myringotomy without an antibiotic has been the common treatment. Moreover, mastoiditis would have developed in more patients during our trial. In the Netherlands antibiotics are likely to be used when otitis takes an unsatisfactory course despite myringotomy. Our patients with a severe course or with persistent discharge after 14 days may have included patients susceptible to mastoiditis in whom antibiotics prevented this complication. Thus antibiotic treatment in this selective group may have contributed to a reduction in the incidence of mastoiditis; this does not, however, explain the difference in incidence between the 1940s and the past decade. The conclusion therefore seems justified that both the decrease in the incidence of mastoiditis and the surprisingly favourable course of acute otitis media treated with nose drops and analgesics alone can be explained by changes in the clinical features of this condition.

In conclusion, treatment of acute otitis media in children can be limited to nose drops and analgesics for the first three to four days. An antibiotic, preferably a penicillin, can be given in the severe cases (still ill after three to four days with persistent high temperature or severe pain, or both) and to patients who do not clinically appear to be ill but still have discharge of the ear after two weeks. Should this treatment not lead to clinical improvement within a few days, further antibiotic treatment should be determined on the basis of a culture. Parents must be instructed to return to the general practitioner if the clinical course is unsatisfactory. If this decision cannot be left to the parents the general practitioner should make a further visit obligatory.

This study was made possible by the cooperation and help of general practitioners in and around Tilburg. We thank them and, in particular, M A M Boormans, $M$ Th M Cottaar, H Dunk, F J H M de Groot, P C G Haenen, J Hilbink, L H M Marres, B Schräder, P P Taminiau, and $W$ Wouts, who acted as liaison officers. We also thank Professor F J A Huygen, Institute for General Practitioners, University of Nijmegen; Professor F Sturmans, departments of social medical science, universities of Nijmegen and Maastricht; and Professor W Kuypers, ear, nose, and throat department, Nijmegen University Hospital, for their encouragement; and our colleagues Dr H Festen and Dr J J W Roovers for their selfless help.

\section{References} myringotomy, antibiotics or neither? Lancet 1981 ;ii:883-7.

Huygen FJA. Gewone ziekten. Rapport van de Werkgroep epidemiologie van he Nijmeegs Huisartseninstituut. Nijmegen: Nijmeegs Huisartseninstituut, 1980 .

Tilles JG, Klein JO, Jao RL, et al. Acute otitis media in children. Serologic studies and attempts to isolate viruses and mycoplasmas from aspirated middle ear fluids. $N$ Engl F Med 1967;277:613-8.

Klein JO, Teele DW. Isolation of viruses and mycoplasmas from middle ear effusions: a review. Ann Otol Rhinol Laryngol 1976;85:140-4.

5 Adlington $P$, Hooper WK. Virus studies in secretory otitis media. $\mathcal{f}$ Laryngol

Otol $1980 ; 94: 191-6$.
Lennette EH, Schmidt NJ. Diagnostic procedures for viral, rickettsial and chlamydial infections. 5th ed. Washington: American Public Health Association, 1979 . the tympanum as a diagnostic and therapeutic method. Acta Otolaryngol [Suppi] (Stockh) 1954;107:1-82.

8 Howie VM, Ploussard JH, Lester RL Jr. Otitis media : a clinical and bacteriological correlation. Pediatrics 1970;45:29-35. Rudberg RD. Acute otitis media. Acta Otolaryngol [Suppl] (Stockh) 1954;113
1-69.

(Accepted 4 December 1984)

\title{
Relation between recurrence of cancer of the colon and blood transfusion
}

\author{
NEIL BLUMBERG, MUKESH M AGARWAL，CHRISTY CHUANG
}

\begin{abstract}
Data suggest that blood transfusion can cause immunosuppression. The incidence of recurrence of tumours was examined retrospectively in patients who had undergone potentially curative operations for cancer of the colon during 1970-81. Tumours recurred in six of 68 patients $(9 \%)$ who had not been given transfusions and in 56 of 129 patients $(43 \%)$ who had $(p \ll 0.0001)$. Transfusion was also found to be significantly associated with the time to
\end{abstract}

\footnotetext{
Department of Pathology and Laboratory Medicine and Division of Biostatistics, University of Rochester Medical Center, Rochester, New York 14642, USA

NEIL BLUMBERG, MD, associate professor of pathology and laboratory medicine

MUKESH M AGARWAL, MD

CHRISTY CHUANG, PHD

Correspondence to: Professor Neil Blumberg.
}

recurrence after adjustment for other baseline prognostic factors $(\mathbf{p}<\mathbf{0 . 0 5})$.

Perioperative transfusion may be a significant risk factor in the prognosis of cancer of the colon. Whether this association is causal is unknown.

\section{Introduction}

Recent clinical and laboratory data obtained in animals agree with the hypothesis that homologous blood transfusion decreases immune responsiveness. ${ }^{1}$ Animal and human recipients of renal transplants have a lower incidence of rejection of the graft if they have previously received blood transfusion. ${ }^{2}{ }^{3}$ Growth of tumours in animals that have received transfusions may be more rapid than in those that have not. ${ }^{5}$ Preliminary data indicate that patients with cancer of the colon who receive blood transfusions have an increased incidence of recurrence of cancer. ${ }^{6}$ We performed a retrospective analysis of transfusions and recurrence in patients with surgically curable cancer of the colon to confirm or refute this initial report. 


\section{Patients and methods}

We retrieved from our hospital's computerised data base the names of all patients discharged with diagnoses of colorectal cancer during 1970-81. From the patient's medical records information was obtained on sex, age, date of operation, duration of operation, location of tumour, packed cell volume on admission to hospital, duration of follow up, use of chemotherapy or irradiation, and recurrence of tumour or death. Operations were performed by many operators, including supervised doctors in training. Information on the history of transfusions and Dukes's stage was obtained from the medical records and confirmed by examination of blood bank records and pathology records, respectively. Lesions confined to mucosa were considered to be Dukes's stage $A$; into but not through the muscularis $B_{1}$; through the muscularis $\mathrm{B}_{2}$; and with regional lymph node metastasis $\mathrm{C}_{\mathrm{i}}$ or $\mathrm{C}_{2}$, depending on whether the colon wall was penetrated. We omitted from the study 466 patients who were operated on elsewhere (377 patients, $81 \%$ ), who were followed up for less than six months after their operation $(28,6 \%)$, who had distant metastases at the time of operation $(42,9 \%)$, or whose records of transfusions were not available. Patients were considered to have had transfusions if they had received any blood product within one month before or after their operation. Duration of operation was defined as the time from induction of anaesthesia to surgical closure as detailed in the anaesthetist's notes. The duration of follow up was defined as the interval in days between operation and the last progress note in the medical record or the date of recurrence or death if this occurred. Patients who died of cancer of the colon within the initial six months' follow up were included in our analysis. A total of 197 patients met the criteria for entry to the study.

\section{STATISTICAL ANALYSIS}

We used $\chi^{2}$ statistics to compare the incidence of recurrence in various groups defined by the variables that were studied. Yates's correction for continuity was applied when analysing two by two tables. ${ }^{7}$ Preliminary results suggested that recurrence was associated with receipt of blood transfusions. The extent of this association, however, was roughly the same regardless of the number of units transfused. Thus the transfusion variable was recorded into two categories-that is, transfusion given or not given. Similarly, duration of operation was regrouped into duration of less than or equal to two hours and greater than two hours. The patient's age was initially categorised into five intervals-that is, $\leqslant 40,41-50,51-60,61-69$, and $\geqslant 71$. Packed cell volume on admission to hospital was used to divide patients into four groups: men with packed cell volume $<0.41$, men with packed cell volume $\geqslant 0.41$, women with packed cell volume $<0.38$, and women with packed cell volume $\geqslant 0.38$. As our data spanned over 10 years we included in our analyses an additional binary variable, year of operation, which indicated whether a patient had the operation before or after 1975. The inclusion of this variable was to adjust for possible differences in the practice of giving blood transfusions.

Age, duration of operation, Dukes's stage, location of tumour, packed cell volume group by sex, and year of operation were included in a multivariate stepwise logistic regression analysis ${ }^{8}$ to identify prognostic factors that would be likely to lead to a patient having to receive a blood transfusion. Kaplan-Meier's product limit estimates for time to recurrence were computed for patients who had received transfusions and those who had not. ${ }^{9}$ Finally, all baseline factors, other than transfusion state, were included in an analysis of time to recurrence, using a proportional hazards model. ${ }^{10}$ Non-significant factors were excluded from the model, leaving only significant ones for time to recurrence. Transfusion state was then added to the proportional hazards model obtained to see whether the change in the log likelihood after including transfusion state was significant. By entering information on transfusions last we could measure the impact of blood transfusion on recurrence after adjustment for other factors. We thus obtained an estimate of the effect on recurrence attributable to blood transfusion state.

\section{Results}

Recurrence or death due to recurrence was seen during follow up in six of 68 patients $(9 \%)$ who had not received a transfusion and in 56 of 129 patients $(43 \%)$ who had $(p \ll 0.0001)$. Estimates of the distributions of the time to recurrence were computed for patients who had received transfusions and those who had not using Kaplan-Meier's product limit method and treating information from patients without recurrence as censored data (figure). Death with recurrence was observed in 22 of the 129 patients who had received transfusions $\left(17^{\circ} \%\right.$ and in three of the 68 who had not $(4 \%)(\mathrm{p}<0.025)$. Among the patien who had received transfusions no significant association was found between incidence of recurrence and the number of transfusions re ceived.

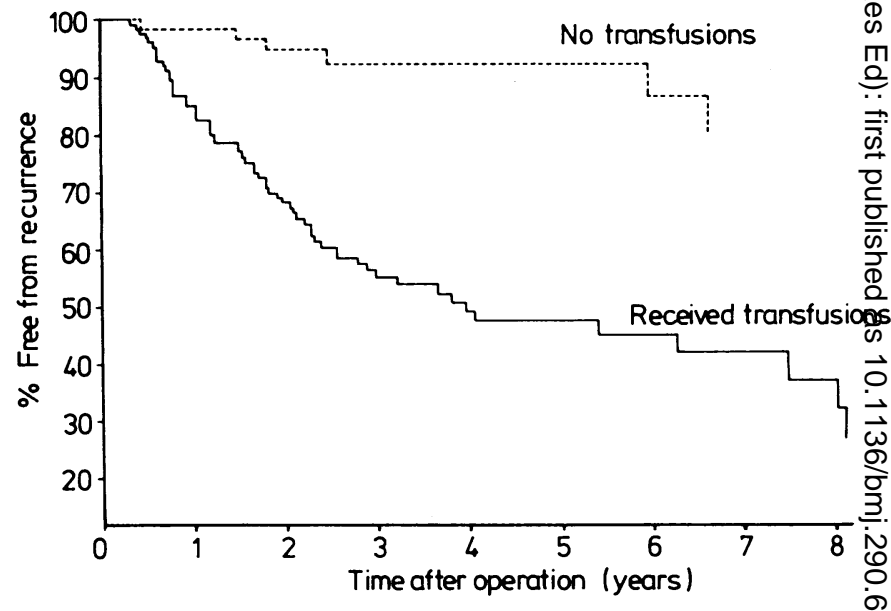

Curves of interval to recurrence in patients with surgically resectabte colorectal cancer, 129 of whom had received transfusions and 68 of whom hat not. Curves are truncated as only five patients who had received transfusio $\vec{\xi}$ and 13 who had not remained at risk after last observed recurrence. Lage censoring occurred at 11.6 years in those who had received transfusions and $9 \cdot 7$ years in those who had not.

Packed cell volume on admission was known in 179 of the 19 patients and was significantly associated with transfusion. Of the 114 patients who had had a transfusion, $86(75 \%)$ had packed cell volumeg on admission that were less than 0.41 compared with 24 of $65(37 \%)$ who had not had a transfusion $(p<0.005)$. Despite the relations b tween incidence of recurrence and transfusion and between transfusio and packed cell volume on admission there was no discernible associ tion between packed cell volume on admission and incidence of recurrence.

Patients who had not received transfusions were less likely to have received chemotherapy or irradiation or both than those who had hat transfusions (seven of 68 patients $(10 \%) v 29$ of $126(23 \%))(p<0.05 \%$ In most of these instances treatment was palliative after recurrence had occurred. The proportion of patients with tumours of Dukes's stage was higher among those who had received a tranfusion than those whe had not (48 of $129(37 \%) v 14$ of $68(21 \%))$. When controlled for Dukes's stage the difference in incidence of recurrence seen wi regard to transfusion state was maintained (table I). Results for stage

TABLE I-Relation between Dukes's stage and recurrence (figures are numbers patients in whom cancer recurred/total in group)

\begin{tabular}{|c|c|c|c|}
\hline & \multicolumn{2}{|c|}{ Dukes's stage } & \\
\hline & $A, B_{1}, B_{2}$ & $\mathrm{C}_{2}$ & \\
\hline $\begin{array}{l}\text { Received transfusions } \\
\text { No transfusions }\end{array}$ & $\begin{array}{c}33 / 81(41 \%) \\
4 / 54(7 \%) \\
p<0.0001\end{array}$ & $\begin{array}{l}26 / 48(54 \%) \\
2 / 14(14 \%) \\
\mathrm{p}<0.02\end{array}$ & $\begin{array}{l}\mathrm{p}=0.19 \\
\mathrm{p}=0.78\end{array}$ \\
\hline
\end{tabular}

p Values determined by $\chi^{2}$ statistics for $2 \times 2$ tables using Yates's correction.

$A, B_{1}$, and $B_{2}$ were combined as the incidence of recurrence for the $\frac{\text { s }}{s e}$ three stages had been found to be similar in an earlier analysis patients in this study.

The proportion of patients with tumours of the rectum or right col@ was higher among patients who had had transfusions (72 out of $1 \frac{1 \mathbb{B}}{B}$ $(64 \%))$ than among those who had not $(18$ out of $64(28 \%))$. When onf patients with tumours of the left colon were considered the difference in incidence of recurrence between patients who had had transfusioes and those who had not was significant $(p<0.0005)$ (table II). IR formation on the location of the tumour was unobtainable or amb guous for 20 patients. 
The incidence of recurrence was found to be significantly higher in patients whose operations lasted two hours or more $(p<0.05)$. When controlled for transfusion state, however, the difference in incidence of recurrence with respect to duration of operation was no longer apparent (table III).

TABLE II-Relation between incidence of recurrence and location of tumour (figures are numbers of patients in whom cancer recurred/total in group)

\begin{tabular}{llll}
\hline & \multicolumn{3}{c}{ Location of tumour } \\
\cline { 2 - 4 } & \multicolumn{1}{c}{ Right colon } & Left colon & \multicolumn{1}{c}{ Rectum } \\
\hline Received transfusions & $17 / 42(40 \%)$ & $17 / 41(41 \%)$ & $17 / 30(57 \%)$ \\
No transfusions & $\mathbf{2} / 14(14 \%)$ & $\mathbf{3} / 46(6.5 \%)$ & $1 / 4(25 \%)$ \\
& $\mathrm{p}=0.14$ & $\mathrm{p}<0.0005$ & $\mathrm{p}=\mathbf{0} .51$ \\
\hline
\end{tabular}

p Values determined by $\chi^{2}$ statistics for $2 \times 2$ tables using Yates's correction.

TABLE III-Relation between incidence of recurrence and duration of operation (figures are numbers of patients in whom cancer recurred/total in group)

\begin{tabular}{|c|c|c|}
\hline & \multicolumn{2}{|c|}{ Duration of operation (hours) } \\
\hline & $<2$ & $\geqslant 2$ \\
\hline $\begin{array}{l}\text { Received transfusions } \\
\text { No transfusions }\end{array}$ & $\begin{array}{c}11 / 24(45 \%) \\
2 / 28(7 \%) \\
\mathrm{p}<0.005\end{array}$ & $\begin{array}{c}40 / 89(45 \%) \\
4 / 36(11 \%) \\
\mathrm{p}<0.001\end{array}$ \\
\hline
\end{tabular}

p Values determined by $\chi^{2}$ statistics for $2 \times 2$ tables using Yates's correction.

To evaluate which factors were significantly associated with receipt of a transfusion a multivariate stepwise logistic regression, using blood transfusion as a binary response variable and age, packed cell volume group, Dukes's stage, location of tumour, year of operation, and duration of operation as predictors, was performed. Only age, location of tumour, duration of operation, and packed cell volume group were significantly associated with blood transfusion after adjustment for other factors $(p<0.05)$. These findings were consistent with the general notion that older people, people undergoing longer operations, and people with preoperative anaemia are more likely to receive blood transfusion. Of the three sites of tumour, tumours in the rectum were associated with the highest incidence of transfusion and in the left colon with the lowest.

A proportional hazards model was fitted to time to recurrence, using all the baseline factors as covariates. Transfusion state was not included in the first set of these models. Tests based on differences in the log likelihood were used to determine whether a particular baseline factor was significant. Of the three locations of tumours, the rectum was associated with the highest risk of recurrence. The two other significant factors (at the 0.05 level) were age $(\leqslant 70$ or $>70)$ and duration of operation ( $\leqslant$ two hours or > two hours). Generally, older people and people with operations that took longer had higher risks of recurrence. When transfusion was added to the proportional hazards model as an additional covariate the log likelihood was increased by 6.81 . The test statistic, derived as $2 \times 6.81$ and compared with a $\chi^{2}$ distribution with one degree of freedom, gave $p<0.0001$. The most significant factor in the above model was the transfusion state. Under this model (with transfusion state as a covariate) the rectum was still the site significantly associated with the highest risk of recurrence. The association between age, duration of operation, and transfusion state, however, made these two baseline factors non-significant once transfusion state was included in the model. The regression coefficients, however, showed identical trends in the risk of recurrence as before. The adjusted relative risk of recurrence by transfusion was 4.23 with $95 \%$ confidence limits of 1.71 and $10 \cdot 48$. This result was consistent with the hypothesis that blood transfusion has a significant effect $(p<0.05)$ on recurrence beyond that attributable to the baseline factors.

\section{Discussion}

Our findings confirmed the results of Burrows and Tartter. ${ }^{6}$ Within the constraints and limitations imposed by our retrospective method, blood transfusion was more closely associated with recurrence of surgically resectable colorectal cancers than previously identified prognostic factors such as Dukes's stage and location of tumour. ${ }^{11}$ Whether this association represents cause and effect is unknown. Clearly, patients who have preoperative anaemia, undergo long operations, or have rectal cancers are more likely to receive transfusions than patients with more favourable clinical circumstances. When taken individually or cumulatively, however, factors such as Dukes's stage, packed cell volume on admission to hospital, and duration of operation are insignificant predictors of recurrence after adjustment is made for transfusion state. It is possible that transfusion state is closely related to some as yet unidentified prognostic factor or factors but is not itself causally related to recurrence.

An incidental finding from the review of our patients' records was that many transfusions were given for indications that were not easily discernible. Many patients with normal preoperative packed cell volumes received one or two units of blood during or after their operation. Table IV shows the numbers of transfusions received by each patient. We do not claim that transfusion

TABLE IV-Number of transfusions given to patients

\begin{tabular}{lrrrrrrrl}
\hline $\begin{array}{l}\text { No of transfusions: } \\
\text { No of patients*: }\end{array}$ & 68 & 21 & 2 & 3 & 4 & 5 & 6 & $\geqslant 7$ \\
\hline
\end{tabular}

*Four patients received transfusions but the exact number of transfusions could not be determined; they are excluded from the table.

is causally related to recurrence of tumours, merely that an association exists and remains unexplained. If subsequent investigations conclude that blood transfusion has deleterious effects in patients with colorectal cancer, toleration of moderate anaemia might result in fewer patients being given transfusions.

Some of this report was presented to the American Association of Blood Banks, New York, 31 October 1983 and published in abstract form (Transfusion $1983 ; 23: 421$ ). This study was supported in part by grants from the National Cancer Institute and the New York State Department of Health AIDS Institute.

We thank Ms Carol Cole for secretarial help and Drs Joanna Heal, John Bennett, and Dean Arvan for helpful discussion.

\section{References}

1 Woodruff MFA, Van Rood JJ. Possible implications of the effect of blood transfusion on allograft survival. Lancet 1983;i:1201-2. 2 Van Es AA, Marquet RL, Van Rood JJ, Balner H. Influence of a single blood transfusion on kidney allo

3 Opelz G, Terasaki PI. Improvement of kidney-graft survival with increased numbers of blood transfusions. N Engl f Med 1978;299:799-803.

4 Francis DMA, Shenton BK. Blood transfusion and tumour growth: evidence from laboratory animals. Lancet 1981 ;ii:871

5 Horimi T, Kagawa S, Ninomiya M, Yoshida E, Hiramatsu S, Orita K. Possible induction by blood transfusion of immunological tolerance against growth of transplanted tumors in mice. Acta Med Okayama 1983;37:259-63

6 Burrows L, Tartter P. Effects of blood transfusions on colonic malignancy recurrence rate. Lancet 1982;ii:662.

Snedecor GW, Cochran WG. Statistical methods. 7th ed. Ames: Iowa State University Press, 1980:124-38, 208-13.

Anderson S, Auquier A, Hauck WW, Oakes D, Vandaele W, Wiesberg HI. Statistical methods for comparative studies. New York: Wiley, 1980:161-77.
Dixon WJ, Brown MB, Engelman L, et al. Angeles: University of California Press, 198

10 Cox DR. Regression models and life tables. Fournal of the Royal Statistical Society, Series $B 1972 ; 34: 187-220$.

11 Sugarbaker PH, Macdonald JS, Gunderson LL. Colorectal cancer. In: De Vita $\mathrm{BT} \mathrm{Jr}$, Hellman S, Rosenberg SA, eds. Cancer: principles and practice of
oncology. New York: Lippincott, 1982:643-723.

(Accepted 18 fanuary 1985) 